\title{
A novel approach for studying gene expression in the cell cycle reveals coordinate and independent regulation of members of the $\mathrm{H} 4$ multigene family in cycling and in nongrowing Tetrahymena
}

\author{
Su-May Yu, ${ }^{1}$ Stuart Horowitz, ${ }^{2}$ and Martin A. Gorovsky \\ Department of Biology, University of Rochester, Rochester, New York 14627 USA
}

The H4 multigene family of Tetrahymena thermophila consists of two genes that code for identical proteins. A quantitative, dot-blot method applicable to intact cells was used to develop techniques for analyzing expression of these (or any other) genes during the cell cycle and in nongrowing cells. Cell cycle stages were determined by cytological analysis of nonsynchronized, growing cells. Upon in situ hybridization with gene-specific probes, both H4-I and H4-II are found to be expressed during macronuclear S phase but only H4-II is expressed during micronuclear $S$. The amount of H4-II mRNA per cell during micronuclear $S$ is considerably less than during macronuclear $S$. The relative amounts of both mRNAs are reduced about 20 - to 30 -fold in nongrowing (starved) cells. Thus, the expression of these two genes can be either coordinate or independent, and both genes function in histone replication and in histone replacement. These results demonstrate that surprising complexity in expression of housekeeping genes can be achieved with an extremely small number of genes in a unicellular eukaryote.

[Key Words: Multigene families; cell cycle; histone genes; in situ hybridization]

Received May 11, 1987; revised version accepted June 30, 1987.

Many (most?) eukaryotic genes that are transcribed into abundant stable or mRNAs are members of multigene families. Three reasons can be advanced for the prevalence of multigene families in eukaryotes. Genes may be repeated for: (1) reasons of gene dosage, to provide necessary amounts of gene products at some stage of the organism's life cycle; (2) functional reasons in cases in which products of similar but nonidentical genes perform related but nonidentical functions; or (3) regulatory reasons in cases in which different genes serve as independently regulated units to ensure properly timed developmental or cell cycle expression in correct amounts.

It is frequently difficult to determine why a particular gene is repeated, and in different organisms (or even within a single organism), members of a given multigene family may exist for different reasons. For example, the tandemly repeated clusters of histone genes in sea urchins and in Drosophila (for review, see Hentschel and

'Section of Plant Biology, Cornell University, Ithaca, New York 148535908 USA

${ }^{2}$ Division of Neonatology, Department of Pediatrics, University of Rochester Medical Center, Rochester, New York 14627 USA.
Birnstiel 1981) are thought to be necessary to provide sufficient messages for rapid division stages of early development, whereas the switch from highly repeated early $\mathrm{H} 4$ and $\mathrm{H} 3$ genes to less repeated ones coding for identical proteins later in sea urchin development (Childs et al. 1982) can only be rationalized in terms of incompletely understood developmental requirements. Recent demonstrations of remarkable evolutionary conservation (Wu et al. 1982; Allis et al. 1986) and particular cytological localizations (Allis et al. 1982; Bhatnagar et al. 1984; Donohue et al. 1986) of quantitatively minor histone $\mathrm{H} 2 \mathrm{~A}$ variants argue strongly for functional variation of histones as well. Alternatively, histone genes can be repeated for no apparent reason, as in the case of the duplicated (but nonidentical) yeast $\mathrm{H} 2 \mathrm{~A}$ or $\mathrm{H} 2 \mathrm{~B}$ genes, either of which is sufficient for normal growth and life cycle progression (see Grunstein et al. 1984).

We have been studying the histone $\mathrm{H} 4$ multigene family of the ciliated protozoan Tetrahymena thermophila. This family consists of two unlinked genes, H4-I and H4-II, both of which are expressed (Bannon et al. $1983,1984)$. Both genes have been cloned and sequenced 
(Bannon et al. 1984; Horowitz et al. 1986) and were found to code for identical $\mathrm{H} 4$ molecules, ruling out the possibility of functional variation at the protein level. In other systems, multiple members of histone multigene families show three patterns of expression (see Schumperli 1986). Most are so-called "replication" histones because they are expressed coordinately only in cycling cells in conjunction with DNA replication. Another class of histone genes code for "replacement" or "basal" histones that are expressed constitutively throughout the cell cycle and in noncycling cells. A third pattern of histone gene expression occurs in some systems in which different members of a multigene family are expressed sequentially in development.

Like most ciliates, Tetrahymena can be grown vegetatively or can be induced by starvation to undergo conjugation, the sexual stage of the life cycle /see Nanney 1980). Initial studies on the expression of the H4-I and H4-II genes indicated that both were expressed in vegetatively growing and in starved gametic cells (Bannon et al. 1983|, indicating that neither gene was expressed in a developmental stage-specific manner.

Ciliates probably diverged early from the phylogenetic lineage giving rise to eukaryotes (see Horowitz and Gorovsky 1985) and are unusual inasmuch as they have two nuclei in each cell-a transcriptionally active, somatic macronucleus and a transcriptionally inert, germinal micronucleus (for review, see Gorovsky 1973). In Tetrahymena, even though $85-90 \%$ of their DNA sequences are indistinguishable (Yao and Gorovsky 1974) and they share a common cytoplasm, the two nuclei have nonoverlapping periods of DNA replication (McDonald 1962; Prescott and Stone 1967; Woodard et al. 1972) in vegetative cells. Since, to our knowledge, no case has been reported in which the transcript of a single gene accumulates twice in a single cell cycle (see Discussion), the simplest hypothesis to explain the existence of two $\mathrm{H} 4$ genes coding for identical proteins in Tetrahymena was that each was expressed in one of the two distinct (macronuclear or micronuclear) S periods. To test this hypothesis, we developed a novel method for quantitating mRNA levels in intact cells (Yu and Gorovsky 1986) and for analyzing mRNA accumulation during the cell cycle. Using these methods, we observed a surprisingly complex pattern of histone gene expression in Tetrahymena, in which both the H4-I and the H4-II genes are coordinately expressed during macronuclear $\mathrm{S}$ and in starved cells whereas only the H4-II gene is expressed during micronuclear S, but at a lower level than during macronuclear $\mathrm{S}$.

\section{Results}

Gene-specific probes for H4-I and H4-II

To quantitate each message independently, the DNA sequences of the transcribed regions of H4-I and H4-II (Bannon et al. 1984; Horowitz et al. 1986) were examined, and relatively nonhomologous regions corresponding to 3 ' transcribed but untranslated regions were subcloned into pGEM vectors, from which probes were derived by in vitro transcription (Fig. 1; see Experimental procedures for details). When used to probe Northern blots (Fig. 2), each of the probes is largely specific for one of the two messages detected previously with an $\mathrm{H} 4$ probe that recognizes both genes (Bannon et al. 1983).

\section{Quantitation of H4-I and H4-II in cycling and in starved cells}

Previous analyses indicated that the total amount of $\mathrm{H} 4$ message in log-phase cells was about 25 times greater than in starved cells ( $\mathrm{Yu}$ and Gorovsky 1986) and that there was no differential loading of the H4-I or H4-II messages onto polysomes of either growing or starved cells (Bannon et al. 1983). To determine whether the amounts of H4-I and H4-II messages are regulated coordinately in different growth states, the relative amounts of each were measured, using a recently described, quantitative dot blot method for intact cells ( $\mathrm{Yu}$ and Gorovsky 1986). Figure 3 demonstrates that the relative amounts of H4-I and H4-II messages in growing and in starved cells are similarly regulated. Previous studies (Bannon et al. 1983) have shown that the relative amounts of total $\mathrm{H} 4 \mathrm{mRNA}$ and of $\mathrm{H} 3$ mRNA in growing and starved cells are the same and that the only $\mathrm{H} 3$ synthesized in starved cells is a minor primary sequence variant referred to as hv2. In studies to be described elsewhere (S. Horowitz and M.A. Gorovsky, in prep.), we have shown that hv2 is homologous to the mammalian replacement variant H3.3. These observations make it likely that the small amounts of $\mathrm{H} 4$ messages found in starved cells code for replacement levels of H4 protein. Since the H4-I and H4-II genes are expressed in starved cells and their messages increase coordinately about 18- and 29-fold, respectively, in growing cells, both genes appear to serve both a replication and a replacement function.

\section{Analysis of the Tetrahymena cell cycle}

The Tetrahymena thermophila cell cycle is unusual inasmuch as the germinal micronucleus and the somatic macronucleus have completely nonoverlapping DNA synthetic periods (see Fig. 4; Woodard et al. 1972). In most organisms, the majority of histone mRNA accumulation during the cell cycle is coupled to (i.e., at the same time as or slightly preceding) DNA replication (for review, see Schumperli 1986). If H4-I and H4-II are indeed expressed coordinately and are cell cycle regulated like histone genes in other organisms, they would have to be expressed twice each cell cycle, once during micronuclear $S$ and once during macronuclear S. Alternatively, the two genes could be expressed noncoordinately, each during one of the two $S$ periods.

No simple method is available to synchronize the complete cell cycle of large numbers of Tetrahymena. However, the micronuclear S period occurs immediately after micronuclear division, during and just after macronuclear division and cytokinesis. Cells with dividing micronuclei, dividing macronuclei, or in varying stages of cytokinesis are easily distinguished and make up 


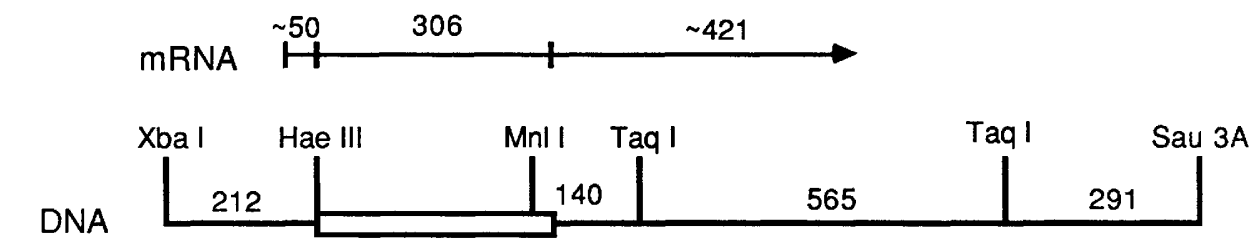

A) $\mathrm{H} 4-\mathrm{I}$
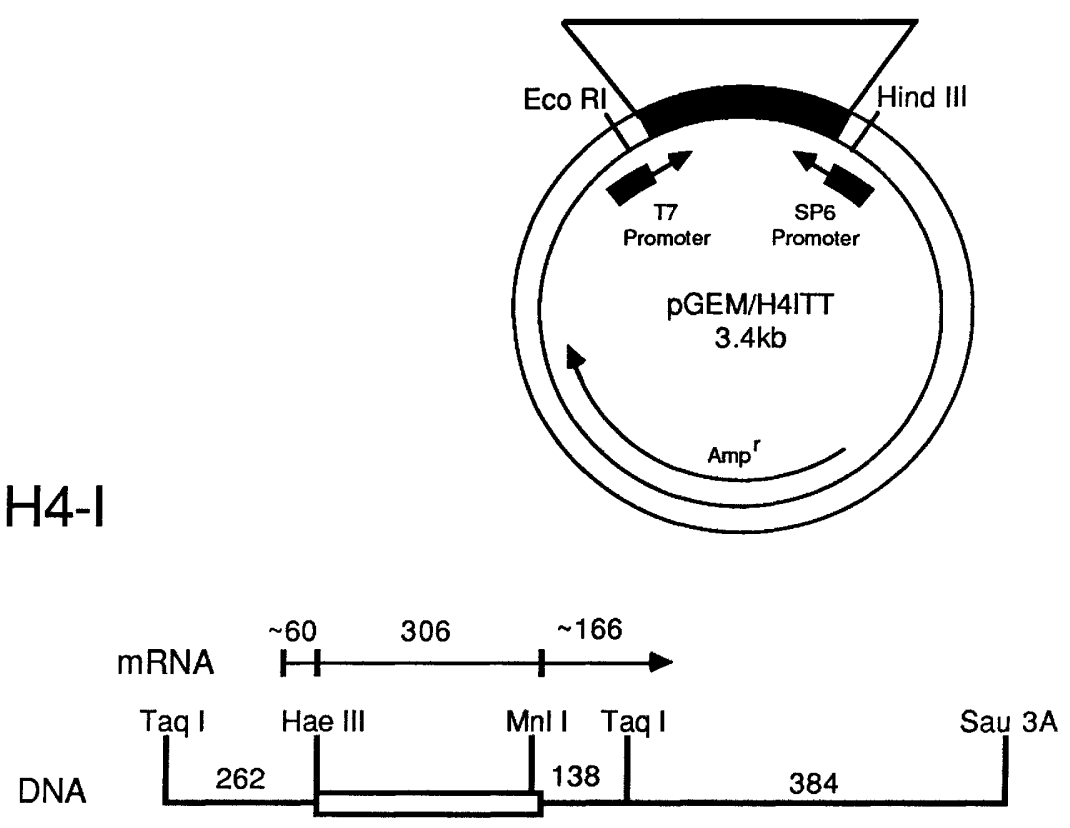

\section{B) $\mathrm{H} 4-\mathrm{II}$}

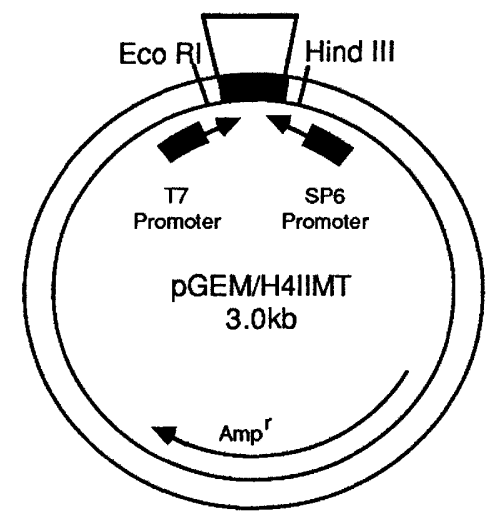

Figure 1. Construction of plasmid vectors containing specific sequences for the H4-I gene $(A)$ or the H4-II gene $(B)$. White areas represent the pGEM-1 sequences. Black areas represent the cloned 3' transcribed but untranslated regions of the Tetrahymena H4 genes. Above each construct is a partial restriction map and a representation of the mRNA divided into 5' untranslated, coding, and $3^{\prime}$ untranslated regions (for details, see Horowitz et al. 1986).

about $15 \%$ of the total cells (Table 1). Thus, cells likely to be in micronuclear $\mathrm{S}$ can be identified. Cells in macronuclear $\mathrm{S}$ cannot be easily distinguished from cells in macronuclear $G_{1}$, or $G_{2}$. However, it is possible to order nondividing cells by size to approximate their position in the remaining $85 \%$ of the cell cycle (see Fig. $4 \mathrm{C}$ and Experimental procedures).

\section{Cell cycle expression of H4-I and H4-II}

Figure 5 (A-E) shows Tetrahymena hybridized in situ with a probe for H4-I. Dividing cells are unlabeled or are labeled only lightly, whereas many nondividing cells are labeled heavily. The simplest interpretation of these observations is that H4-I message accumulates considerably over its basal level during macronuclear S, but little if at all during micronuclear S. Tetrahymena hybridized with $\mathrm{H} 4-\mathrm{II}(\mathrm{G}-\mathrm{K})$ show both clearly labeled dividing cells and heavily labeled nondividing cells, suggesting that H4-II mRNA accumulates above basal levels twice during the cell cycle, once during macronuclear $S$ and once during micronuclear $\mathrm{S}$.

Quantitative analyses strongly support the above in- 


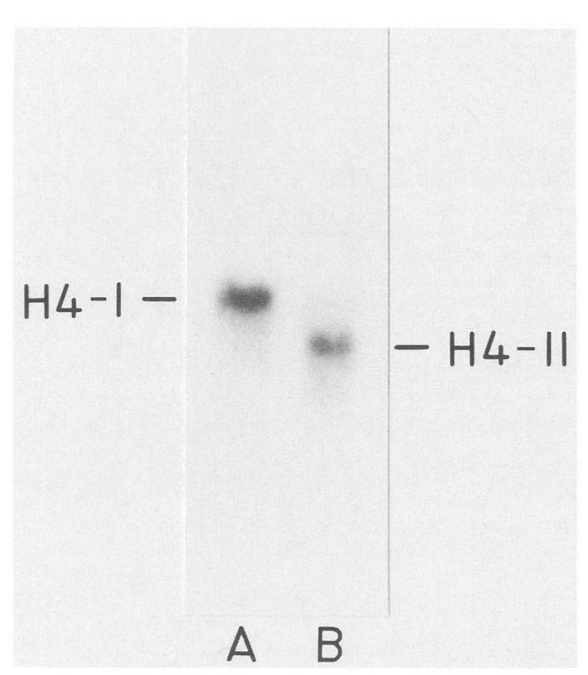

Figure 2. Northern blot demonstrating the specificity of the H4-I $(A)$ and H4-II $(B)$ probes. RNA (15 $\mu \mathrm{g} /$ lane) isolated from growing cells was run on an agarose gel and blotted to nitrocellulose (see Experimental procedures). The blot was probed with H4-I or H4-II antimessage transcripts. The sizes of the H4-I ( $\sim 850 \mathrm{bp})$ and H4-II ( $\sim 600 \mathrm{bp})$ messages agree with previous estimates by transcript mapping (Horowitz et al. 1986).

terpretation. When cell cycle stages are determined by a combination of cytological staging and cell size, grain counts indicate that $\mathrm{H} 4-\mathrm{II}$ but not H4-I message accumulates in cells about when micronuclear $\mathrm{S}$ is known to occur, whereas both messages accumulate in nondividing cells in a manner completely consistent with their being coordinated with macronuclear S (Fig. 6A,B). Thus, direct cytological observations (Fig. 5) and quantitative analyses (Fig. 6A,B) indicate that $\mathrm{H} 4$-II but not $\mathrm{H} 4-\mathrm{I}$ accumulates during micronuclear $\mathrm{S}$. However, the fact that macro- and micronuclear $S$ are separated by only about $6 \%$ of the cell cycle (D. Allis, pers. comm.) and the variability in the data make it difficult to determine whether there are two distinct periods of enhanced H4-II expression or simply a single accumulation that starts earlier in the cell cycle for H4-II than for H4-I. Two approaches were employed to help resolve this issue. In the first, the ratio of H4-II grains/cell to H4-I grains/cell was plotted versus cell cycle (Fig. $6 \mathrm{C}$ ). Relative to H4-I, a distinct period of accumulation during micronuclear $\mathrm{S}$ is observed, followed by a drop to a relatively constant ratio for the remainder of the cell cycle. In the second approach, a more intensive analysis of the earlier stages of the cell cycle was carried out using a longer autoradiographic exposure (Fig. 7). Again, a distinct peak of H4-II message accumulation is indicated. Given these observations, we strongly favor the interpretation that the H4-II message accumulates at two distinct periods of the cell cycle. It is also clear from these experiments that less H4-II mRNA accumulates during micronuclear $\mathrm{S}$ than during macronuclear $\mathrm{S}$.

\section{Discussion}

We have analyzed the cell cycle expression of the H4-I and H4-II genes using a novel and extremely simple combination of in situ hybridization and cytological analysis. The method does not require synchronized cells or highly specialized equipment and should be applicable to small numbers of most cell types whose size increases continuously during the cell cycle. In fact, mitotically dividing cells, which partition their nuclear DNA more precisely than amitotically dividing Tetrahymena macronuclei, might be expected to have their sizes correlate even better with position in the cell cycle. The optimum methods for in situ hybridization to any cell type can be established easily and quickly, utilizing a recently described, quantitative dot blot method for suspended whole cells (Yu and Gorovsky 1986) or related methods applicable to anchored cells (Singer et al. 1986). Alternatively, it may be possible to analyze gene
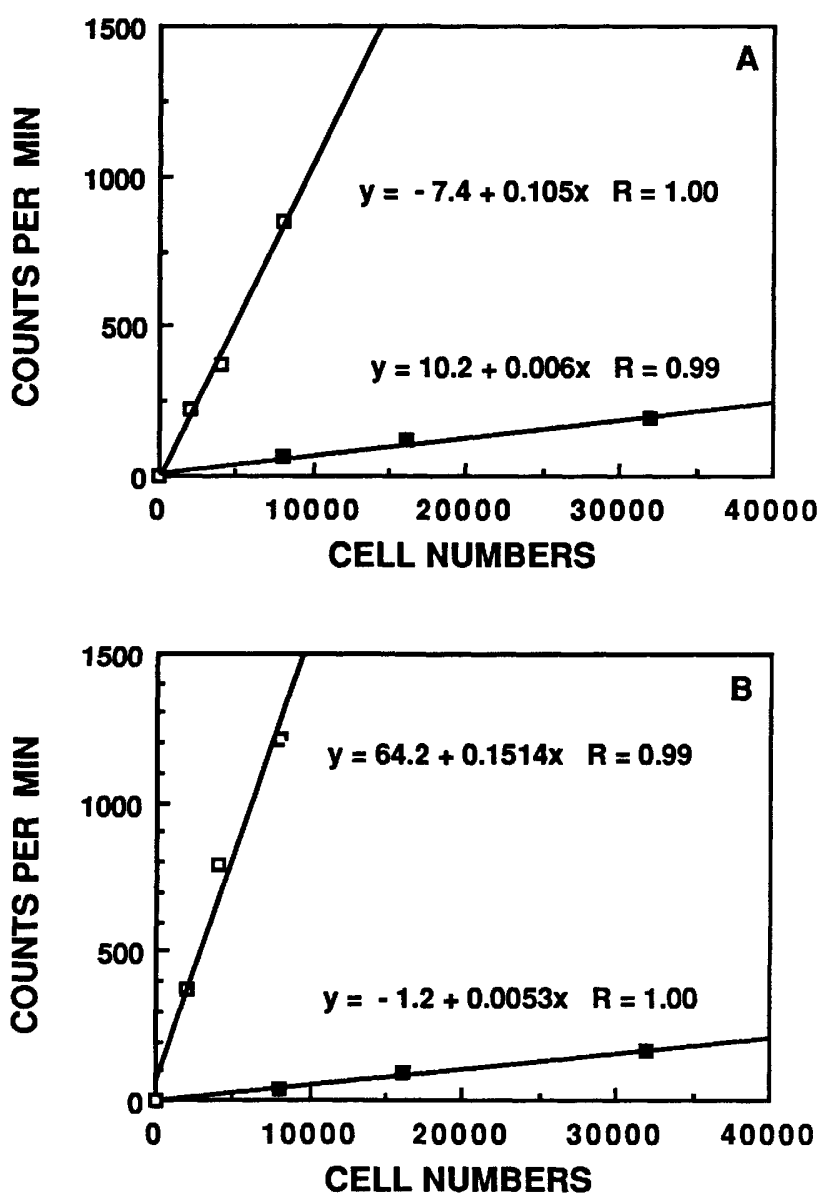

Figure 3. Determination of the relative amounts of H4-I $(A)$ and H4-II $(B)$ messages in growing and starved cells. Varying numbers of growing ( $\square$ ) or starved cells ( $\square$ ) were spotted onto polylysine-coated glass filters and hybridized with probes for H4-I or H4-II. Slopes of the lines are proportional to mRNA per cell. Note that comparisons can only be made between two cell types hybridized to the same probe, since no attempt was made to obtain identical kinetic conditions for the two probes. 


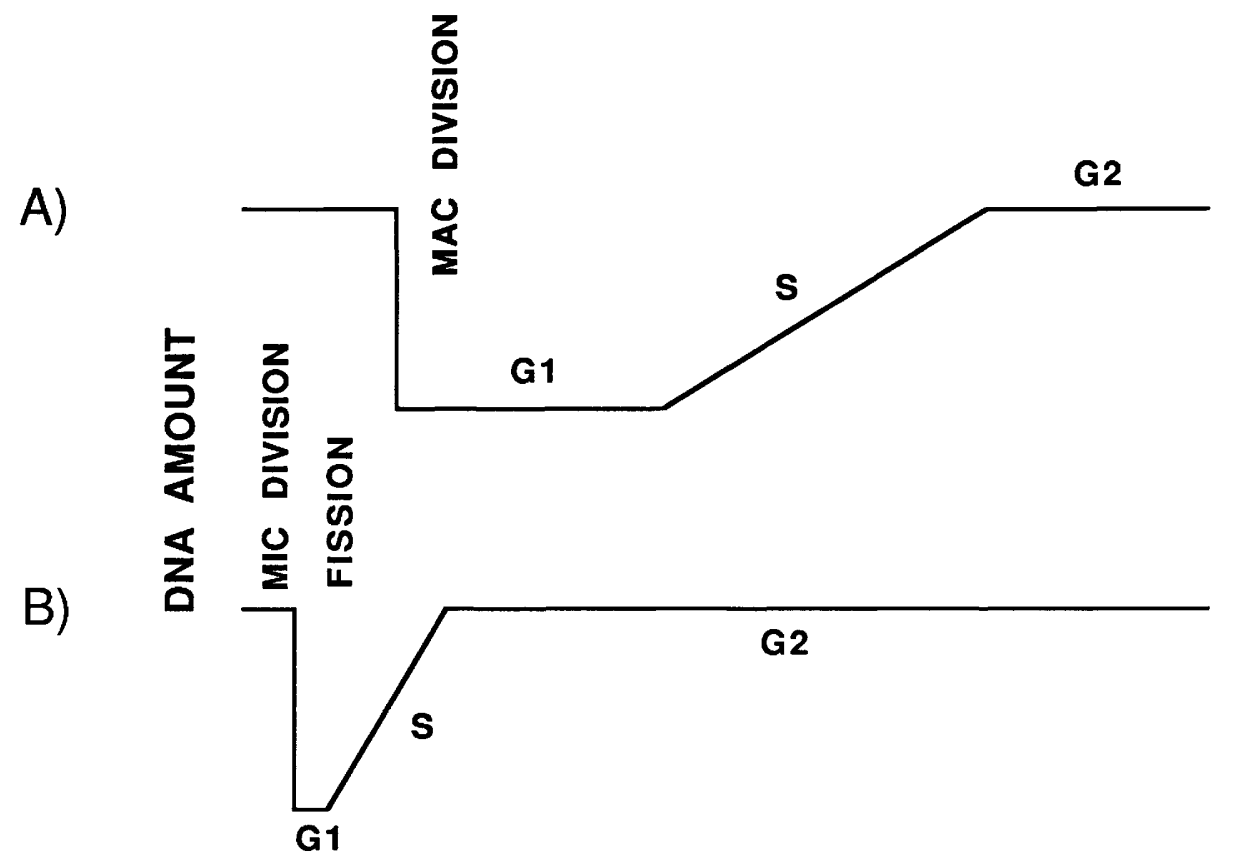

C)

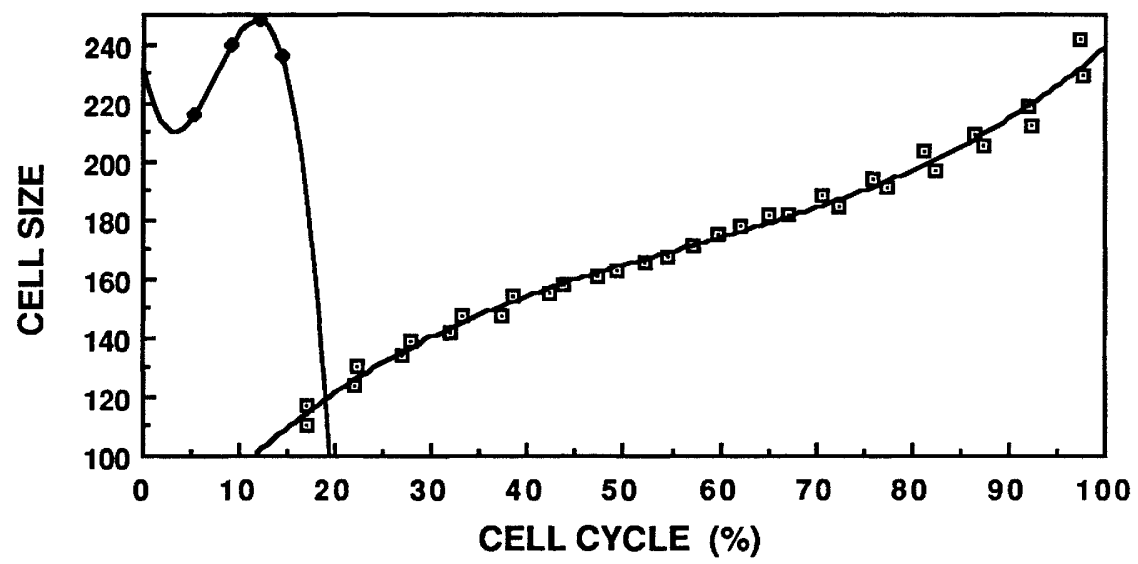

Figure 4. Comparison of the macronuclear $(A)$ and micronuclear $(B)$ division-replication cycle with the cell cycle $(C)$ determined by analyzing the fraction of dividing cells $(\$)$ and of nondividing cells $(\square)$ of different sizes from the slides hybridized with H4-I or H4-II. The cell cycle diagrams in $A$ and $B$ are redrawn from Woodard et al. (1972). Percentages of dividing cells used to calculate position in the cell cycle are those listed in Table 1. Percentages of nondividing cells are obtained by dividing the total number of nondividing cells into 16 equal-sized classes and multiplying the fraction of cells in each class by the fraction of nondividing cells (see Experimental procedures). Note that we have started the cell cycle with cells in micronuclear division and have simply determined position in the cell cycle as the cumulative fraction (expressed as a percentage) of the total cells to that point.

expression during the cell cycle by separating fixed cells on the basis of size (i.e., by elutriation, cell sorting, or sedimentation at unit gravity) and simply quantitating the mRNA contents of intact cells by in situ dot blots (Yu and Gorovsky 1986). We are currently exploring this possibility.

Three patterns of regulation of members of a histone multigene family have been described previously in multicellular eukaryotes (for review, see Schumperli 1986): coordinate with DNA replication, independent of DNA replication, and sequential. The two genes in the Tetrahymena $\mathrm{H} 4$ multigene family exhibit all three patterns of expression. The expression of H4-I and H4-II during macronuclear $\mathrm{S}$ and in nongrowing cells appears to be both temporally coordinated and quantitatively similar. H4-I and H4-II messages accumulate in conjunction with macronuclear DNA replication. Both genes are also expressed at low levels in nongrowing cells, where their message amounts are similar to those of the replacement histone variant hv2 (Bannon et al. 1983). Thus, both H4-I and H4-II function as both basal/ replacement-type and replication-type histone genes. It is not known whether individual $\mathrm{H} 4$ genes in other systems similarly serve both a replication-related and a replacement/basal function. A low rate of histone synthesis is detectable at times other than S phase in many 
Yu et al.

Table 1. Fraction of dividing and nondividing cells in a growing culture of Tetrahymena thermophila

\begin{tabular}{|c|c|c|}
\hline Morphology & Number of cells & Percent \\
\hline $\begin{array}{l}\text { Micronuclear } \\
\text { division }\end{array}$ & 56 & 5.4 \\
\hline $\begin{array}{l}\text { Divided } \\
\text { micronucleus }\end{array}$ & 39 & 3.7 \\
\hline $\begin{array}{l}\text { Macronuclear } \\
\text { division }\end{array}$ & 31 & 3.0 \\
\hline Cytokinesis & 24 & 2.3 \\
\hline $\begin{array}{l}\text { Nondividing } \\
\text { cells }\end{array}$ & 894 & 85.6 \\
\hline Total & 1044 & 100.0 \\
\hline
\end{tabular}

mammalian tissue culture cells (see Wu et al. 1984), but except for a few cases in which the histone proteins clearly differ, little information is available on whether the proteins resulting from such basal/replacement synthesis are products of the same genes that are expressed during $\mathrm{S}$ phase.

Given that H4-I and H4-II message accumulation is regulated similarly during macronuclear $S$ and in starved cells, it was surprising to observe that the two genes could also be regulated independently during micronuclear S. Independent regulation of members of the $\mathrm{H} 4$ multigene family has also been described in sea urchins, where a developmental switch occurs from early to late genes (see Childs et al. 1982).

We can only speculate about the mechanisms underlying the complex regulation of these two genes. Coordinate expression could be mediated by one or more of a number of short sequence elements that are found both upstream and downstream of both the H4-I and H4-II coding regions (Horowitz et al. 1986). Some element not shared by the two genes is likely to be responsible for the unique expression of $\mathrm{H} 4-\mathrm{II}$ in conjuction with micronuclear S. Interestingly, the H4-II gene is linked closely (within $350 \mathrm{bp}$ ) to a divergently transcribed $\mathrm{H} 3$ gene (H3-II; Horowitz et al. 1986). The expression of H4-II and H3-II differs in starved cells inasmuch as the H3-II message is not detectable (Bannon et al. 1983). It will be of interest to see if $\mathrm{H} 3-\mathrm{II}$ is coordinately expressed with H4-II during micronuclear S. Hopefully, by correlating the patterns of expression and the sequence homologies of different Tetrahymena histone genes and their flanking regions, it will be possible to identify elements regulating cell cycle-specific expression that warrant more detailed analyses.

Transcripts of a number of genes in a variety of cell types are cell cycle regulated (for review, see Kaczmarek
1986), but, to our knowledge, the accumulation of the H4-II gene message twice in the cell cycle is unique. Clearly, gene expression at multiple points in the cell cycle can be regulated by mechanisms that do not involve changes in message abundance, as in the case of the cdc2 gene of Schizosaccharomyces pombe, which functions twice during the cell cycle without any change in the level of its transcript (Durkacz et al. 1986). Further studies are necessary to determine the level (transcriptional or post-transcriptional) at which regulation occurs. Differential splicing cannot occur, since neither H4-I nor H4-II have introns. Both H4-I and H4-II transcripts have multiple $5^{\prime}$ ends and a single $3^{\prime}$ end (Horowitz et al. 1986). Analysis of the $5^{\prime}$ and $3^{\prime}$ ends of $\mathrm{H} 4-\mathrm{II}$ messages in growing and starved cells (Horowitz et al. 1986; J. Bowen and M. Gorovsky, unpubl.) failed to reveal any evidence for alternate processing. Thus, it seems likely that the complex pattern of expression of $\mathrm{H} 4$ genes in Tetrahymena will be mediated by the action of specific factors acting either on transcription or on message stability.

Finally, we can return to the question of why there are two histone $\mathrm{H} 4$ genes in Tetrahymena. Clearly, the H4-II gene alone shows all of the features necessary for complete cell cycle regulation during both $S$ periods and for replacement synthesis. Barring a unique role for H4-I during the sexual phase of the life cycle, the simplest explanation for the existence of $\mathrm{H} 4-\mathrm{I}$ is that it is required for reasons of gene dosage during macronuclear $S$, when the cells must rapidly accumulate more than 40,000 messages per cell ( $\mathrm{Yu}$ and Gorovsky 1986) from approximately 45 genomes (Woodard et al. 1972) in the endoreplicated macronucleus.

\section{Experimental procedures}

\section{Preparation of cells}

Tetrahymena thermophila (strain CU 399) were grown axenically as described (Gorovsky et al. 1975). Cells were starved, harvested, fixed, and immobilized using the dot blot procedures recently described by Yu and Gorovsky (1986). For in situ hybridization a drop of the cell suspension $\left(1 \times 10^{6} \mathrm{cells} / \mathrm{ml}\right)$ in $70 \%$ ethanol was spread on a poly-L-lysine $(50 \mu \mathrm{g} / \mathrm{ml}$ in $10 \mathrm{mM}$ Tris, $\mathrm{pH}$ 8.0) -coated glass slide and air-dried. Pretreatment of cells was performed by a modification of the method of Angerer and Angerer (1981). Briefly, slides were incubated with proteinase $\mathrm{K}(8 \mu \mathrm{g} / \mathrm{ml}$ in $50 \mathrm{~mm}$ EDTA, $100 \mathrm{~mm}$ Tris- $\mathrm{HCl}, \mathrm{pH} 8.0$ ) at $37^{\circ} \mathrm{C}$ for $1 \mathrm{hr}$, rinsed in proteinase $\mathrm{K}$ buffer, and immersed in $0.1 \mathrm{M}$ triethanolamine $(\mathrm{pH} 8.0)$ for $10 \mathrm{~min}$ at room temperature, followed by $0.25 \%$ acetic anhydride in $0.1 \mathrm{M}$ triethanolamine for $10 \mathrm{~min}$ at room temperature. Slides were then rinsed in $2 \times$ SSC $(20 \times \mathrm{SSC}$ is $3.0 \mathrm{M} \mathrm{NaCl}+0.3 \mathrm{M}$ sodium citrate, $\mathrm{pH} 7.0)$ and dehydrated through $30,50,70,85,99$, and $99 \%$ ethanol.

\section{Preparation of probes}

A TaqI-TaqI fragment of 565 bp carrying the 3 ' transcribed but untranslated region of the Tetrahymena histone H4-I gene was purified from plasmid p508.8 (Bannon et al. 1984). It was ligated into the AccI site of plasmid pGEM-1 (Promega Biotec) to yield plasmid pGEM/H4ITT. A MnlI-TaqI fragment of 138 bp carrying the $3^{\prime}$ transcribed but untranslated region of the histone 
H4 gene expression in Tetrahymena

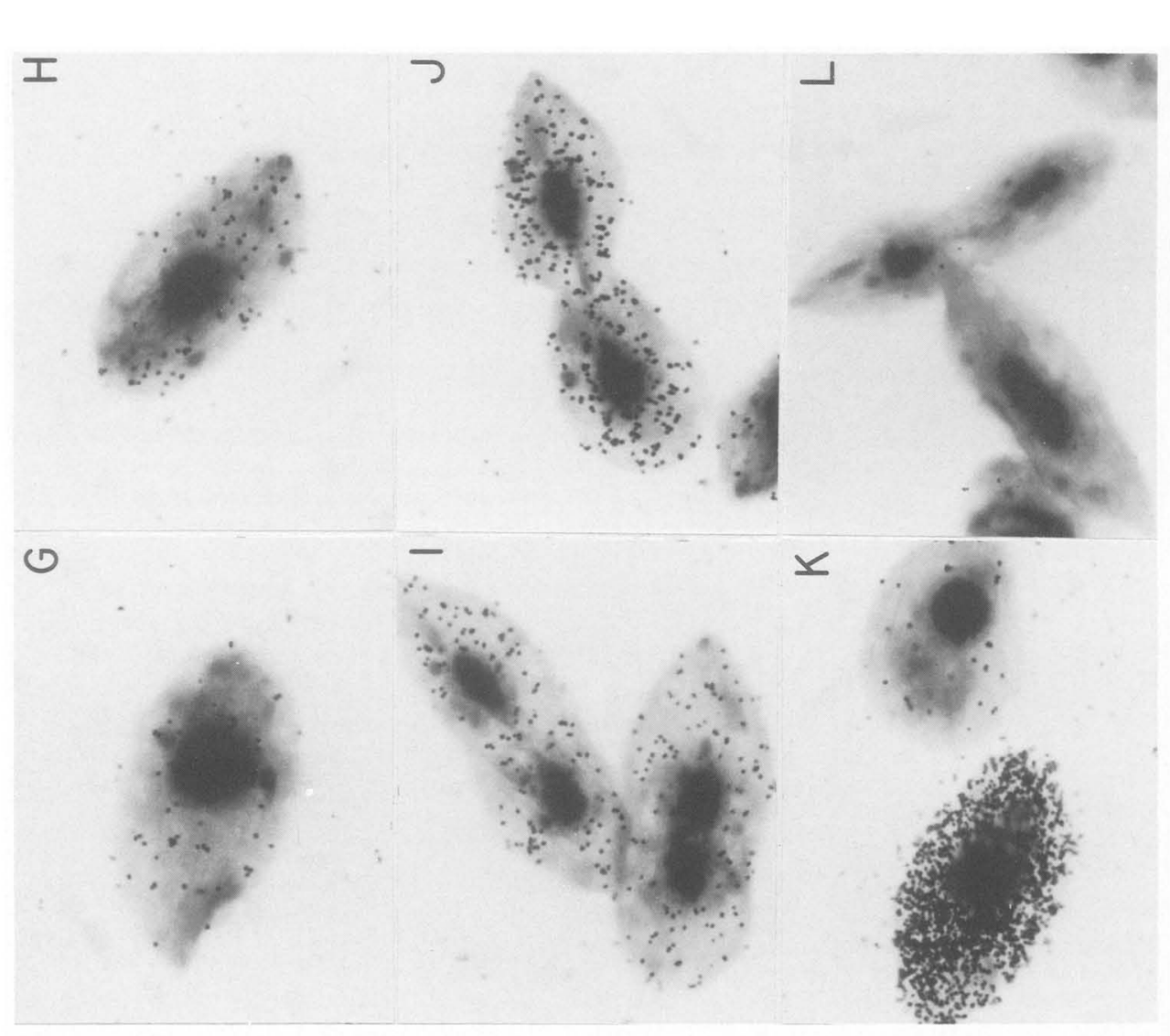

$\infty$

$m$

$\varangle$

8.

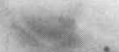

$\because 2 ;$

(1)

i

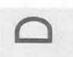

$\square$
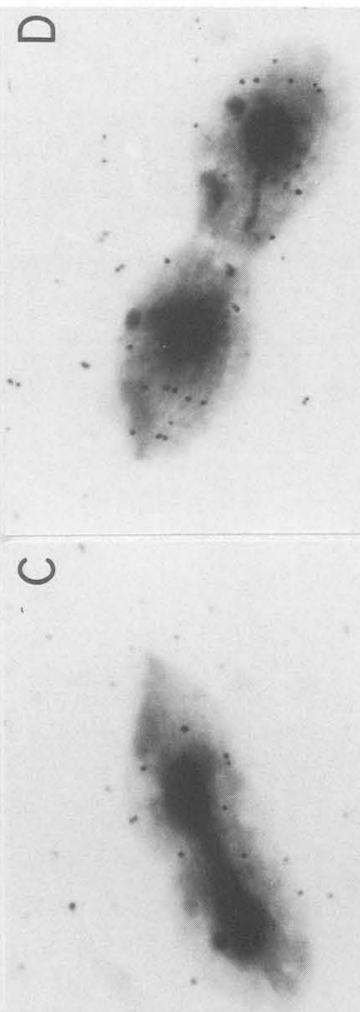

U

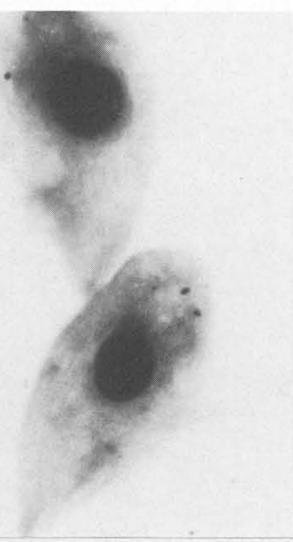

ш

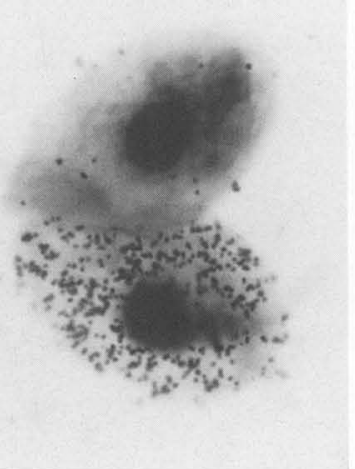

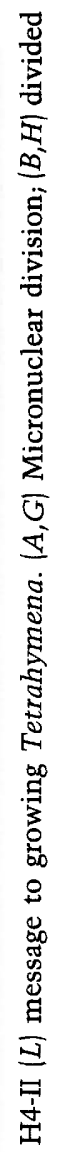

守密

สํ.

.

密

这

突 近

$\overline{4} \cdot \bar{m}$

ㄴ․․

装莡

둥

S

守它

䑰

家

교

过

로

昰峏

毛害

in

in 
H4-II gene was purified from plasmid pSH 999.12 (Horowitz et al. 1986). It was ligated into SmaI- and AccI-cut plasmid pGEM-1 to yield plasmid pGEM/H4IIMT. Transcription of pGEM-H4ITT or pGEM/H4IIMT with SP6 RNA polymerase yields antimessage-strand transcripts complementary to cellular mRNA. Transcription of pGEM/H4ITT or pGEM/H4IIMT with T7 RNA polymerase yields message-strand transcripts. Figure 1 shows the construction of the two plasmids.

Transcription reactions were carried out according to procedures described previously (Yu and Gorovsky 1986). The specific activity of the tritium-labeled probes was about $4 \times 10^{7}$
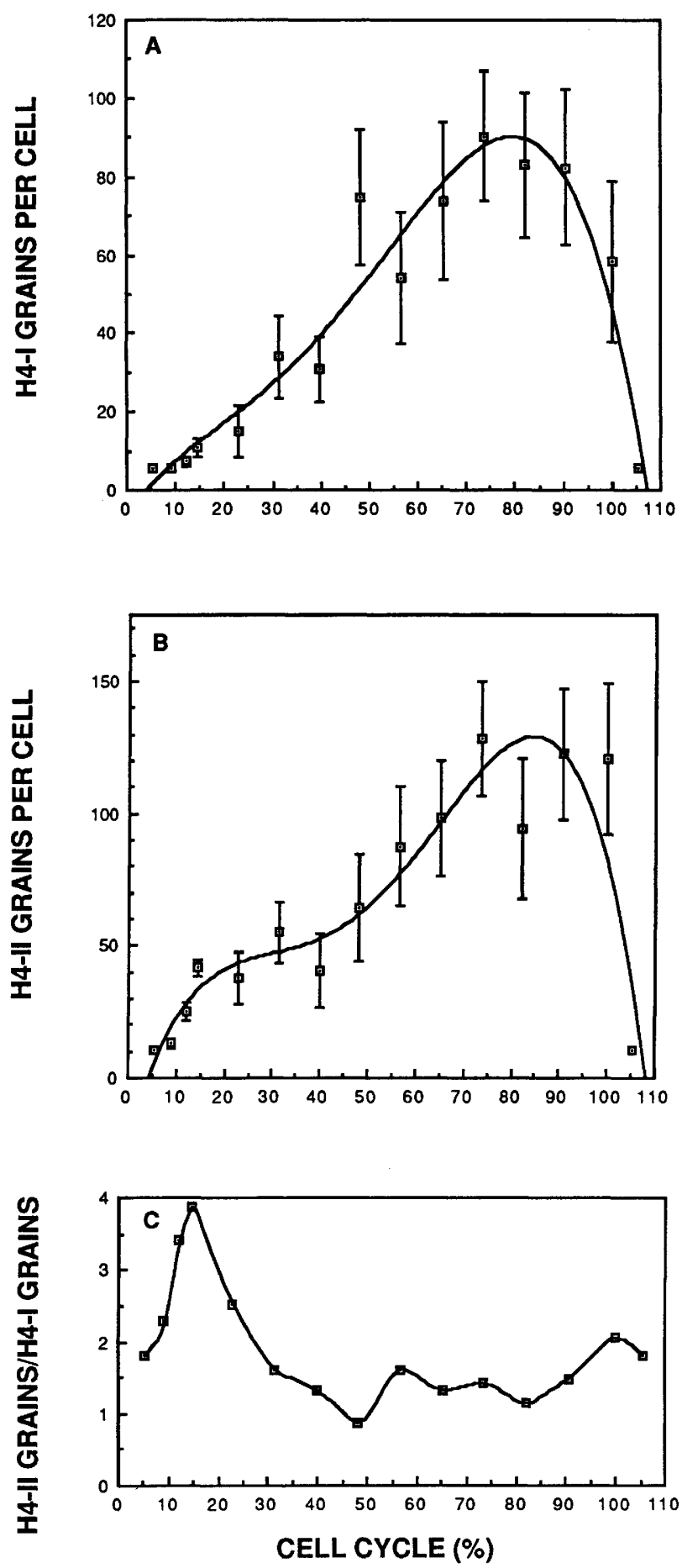

$\mathrm{cpm} / \mu \mathrm{g}$. ${ }^{32} \mathrm{P}$-Labeled probes had a specific activity of about $2 \times 10^{7} \mathrm{cpm} / \mu \mathrm{g}$. The lengths of denatured transcripts were determined by agarose gel electrophoresis (Carmichael and McMaster 1980; Thomas 1983). The fragment sizes of RNA probes were adjusted to a mass average of approximately 150 bases by limited alkaline hydrolysis (Cox et al. 1984).

\section{Whole-cell RNA purification and Northern blot}

Tetrahymena RNA was isolated by a modification of the method described by Calzone et al. (1983). Briefly, $2.5 \times 10^{5}$ growing cells were harvested in $50-\mathrm{ml}$ conical tubes by centrifugation at $1500 \mathrm{~g}$ for $2 \mathrm{~min}$. Cell pellets were combined, washed once with fresh culture medium, added to $80 \mathrm{ml}$ of urea buffer $17 \mathrm{~m}$ urea, $2 \%$ SDS, $20 \mathrm{mM} \mathrm{NaAc}$, and $10 \mathrm{mM}$ EDTA, $\mathrm{pH}$ 7.0) at room temperature, and homogenized in a Dounce homogenizer. The homogenate was then incubated with 0.5 $\mathrm{mg} / \mathrm{ml}$ proteinase $\mathrm{K}$ for $30 \mathrm{~min}$ at $65^{\circ} \mathrm{C}$, and $1 \mathrm{~g} / \mathrm{ml} \mathrm{CsCl}$ was added. The homogenate was then laid over $1.7 \mathrm{~g} / \mathrm{ml} \mathrm{CsCl}$ in water and centrifuged at $38 \mathrm{~K} \mathrm{rpm}$ in a Beckman $60 \mathrm{Ti}$ rotor for $24 \mathrm{hr}$ at $25^{\circ} \mathrm{C}$. The RNA pellet was resuspended in water, ethanol-precipitated, and resuspended in water. RNA blot analysis was performed as described by Thomas (1983). An RNA ladder from Bethesda Research Laboratories was used as marker.

\section{Hybridization}

Dot blot hybridizations were performed as described by Yu and Gorovsky (1986). This method gives quantitative results on relatively small numbers of intact cells. In situ hybridization was carried out as described by Cox et al. (1984). Autoradiography was performed as described by Angerer and Angerer (1981). The cells were stained with $1 \%$ Giemsa (Sigma) in $10 \mathrm{~mm}$ phosphate buffer ( $\mathrm{pH} 6.5$ ) for $15 \mathrm{~min}$. Exposure times were 2-4 weeks. As expected, hybridization with message strand gave little or no signal (Fig. 5F,L). Grains were counted directly from a video monitor connected to an Olympus $\mathrm{BH}-2$ microscope equipped with an Ikegami ITC-48 Surveillance television camera. The grain counts have been corrected for nonspecific background binding.

\section{Cell cycle analysis}

Dividing cells, or cells containing dividing or divided micronuclei or macronuclei, could be identified cytologically and were divided into four consecutive stages that accounted for about $15 \%$ of the cells encountered randomly (Table 1). The position of each class of dividing cells in the cell cycle is simply the fraction (expressed as a percentage) of cells in that stage plus

Figure 6. Accumulation of H4-I $(A)$ and H4-II $(B)$ messages during the cell cycle in Tetrahymena thermophila. Average grain counts (grains/cell) were determined for groups of dividing and nondividing cells and plotted versus position in the cell cycle as determined in Fig. $4 \mathrm{C}$, except that average values (size, grains) for groups of 17 interphase cells were calculated for H4-II and groups of 16 for H4-I. Autoradiographic exposures were for 2 weeks. $(A)$ H4-I message accumulation; (B) H4-II message accumulation. Values are means \pm standard errors. Where error bars are not visible, they are completely contained within the symbol marking that point. Curves were fit with a fourth-order polynomial; higher-order fits gave similar results. Note that the first point $(5.4 \%)$ in the cell cycle is repeated at $105.4 \%$ to allow complete visualization of the macronuclear $\mathrm{S}$ period; $(C)$ ratio of $H 4-I I$ grains to H4-I grains. 


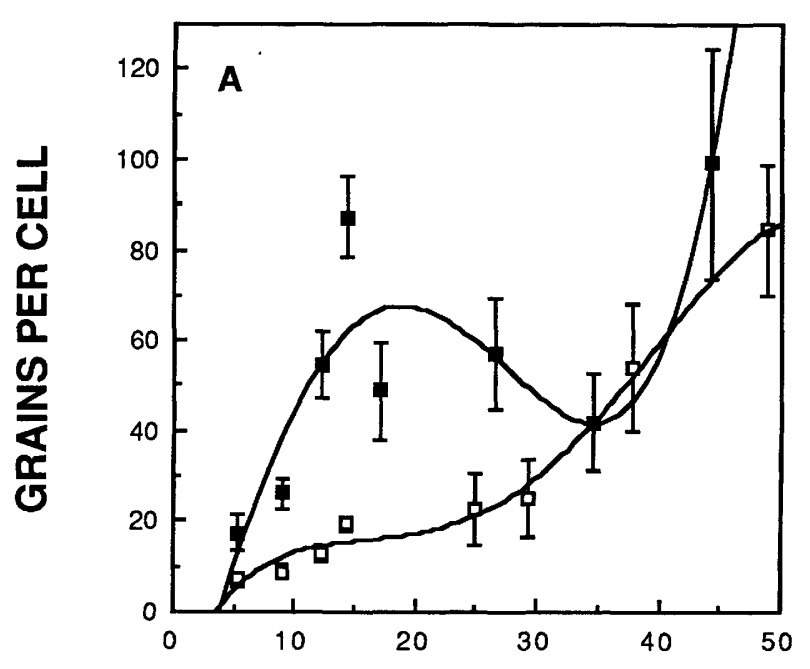

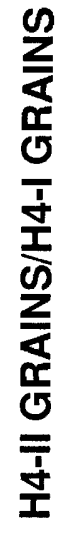

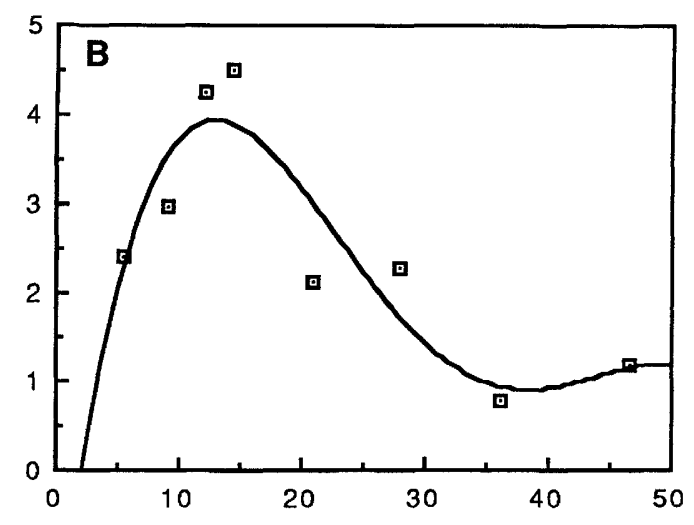

\section{CELL CYCLE (\%)}

Figure 7. Comparison of H4-I ( $\square$ ) and H4-II ( $\square$ ) message amounts in early stages of the cell cycle. Average grain counts of 63 (H4-I) and 54 (H4-II) staged dividing cells and of 60 (H4-I) and 60 (H4-II) small nondividing cells were plotted against position in the cell cycle. In this experiment, no attempt was made to select cells randomly. Dividing cells and smaller nondividing cells were sought and measured, and grains were counted. The cell sizes of the nondividing cells were ordered, and the average size of every 15 cells was determined and used to estimate the position of that group of cells in the cell cycle, using the data in Fig. 4C. Autoradiographic exposure was for 4 weeks, resulting in approximately twice the grain density of comparably sized cells exposed for 2 weeks as in Fig. 6. $|A|$ H4-I and H4-II message accumulation; $(B)$ ratio of $\mathrm{H} 4-\mathrm{II}$ grains to H4-I grains. Curves were fit with a fourth-order polynomias.

the fraction in all preceding stages. Cells showing elongated micronuclei are arbitrarily taken as the first stage. The cell cycle stage of the remaining $85 \%$ of the cells was estimated by size. The outlines of all randomly encountered nondividing cells whose grains were counted (see above) were traced on transparent imagemaker line sheets laid over the television screen, and areas of cells were measured with a Tektronix digi- tizer (Model 4956)-controller (Model 4052). Since cells appeared quite flat under the microscope, we have treated them as uniformly flattened discs in which cell volume is directly proportional to the measured areas. The measured cells were then arranged in rank order according to size. Most of the cells are seen to be on a reasonably straight line ranging in size from approximately that of dividing cells to about one-half that of the dividing cells. A few cells at the very top and the very bottom of the distribution appear to be unusually large and small, respectively. It is well known that the amitotic macronuclear division is somewhat imprecise, so that some cells in any large population contain significantly more or significantly less DNA than the average. In these cases, Tetrahymena maintains upper and lower limits on the DNA amount per macronucleus either by undergoing two rounds of DNA replication without an intervening cell division or by undergoing division without DNA replication (for discussion, see Doerder 1979). Cells that have just undergone one of these two events are likely to be unusually large or unusually small. Such cells are rare but could account for the cells at the extremes of the distribution shown in Figure 4.

To determine the cell cycle stage of the remaining nondividing cells, the average size of every 10 cells was determined and plotted against their position in the cell cycle (Fig. 4C). After ordering the cells by size, the nondividing cells were divided into equal-sized groups. Position in the cell cycle was calculated simply as the fraction of nondividing cells in that size group times 0.85 plus the fraction of cells in all preceding stages. Note that only two assumptions underlie this analysis. First, we have assumed that the frequency of any particular size class or cytologically staged class of cells is proportional to the fraction of the cell cycle spent at that stage. Although this analysis can be slightly refined mathematically (Mitchison 1971), it is a simple, frequently used way to approximate the cell cycle. Second, by staging cells according to size we have assumed that cells grow continuously during the cell cycle. The data in Figure $4 \mathrm{C}$ are consistent with that hypothesis. The sizes of the nondividing cells extend over a twofold range, consistent with a doubling of cell size every generation, and the largest nondividing cells are similar in size to the next stage in the cell cycle, dividing cells. Also, the data in Figure $4 \mathrm{C}$ are reasonably continuous. If cells stopped growing or shrank during interphase, some particular cell sizes should have been overrepresented and a portion of the curve might have been expected to have a zero slope. Even the slight decrease in size observed between cells early and late in cytokinesis (Fig. $4 \mathrm{C}$ ) has a reasonable explanation in known features of the Tetrahymena division cycle. Dividing cells do not feed (see Hill et al. 1986) and, therefore, might be expected to shrink slightly. These observations are completely consistent with previous studies in a different species of Tetrahymena that demonstrate that both volume (Cameron and Prescott 1961) and newly synthesized protein (Prescott 1960) accumulate continuously throughout the cell cycle, largely in a linear fashion.

Although cell size provides an adequate basis for staging cell cycle events for the studies reported here, it is nonetheless an imperfect mechanism for staging cell cycle events in interphase Tetrahymena. Clearly the variability in grain counts (see Figs. 6 and 7) for dividing cells staged by morphological criteria is significantly smaller than for cells staged by size. Whether this variability is biological or technical is not known at this point.

It is worth noting that once the curve in Figure $4 \mathrm{C}$ is established by randomly measuring an adequate number of cells, the position of any cell in the cell cycle can be estimated simply by noting its morphology or by measuring its size (see Fig. 7). This method of cell cycle analysis should be applicable to any cell that grows continuously during the cell cycle, is applicable to 
very small numbers of unsynchronized cells, and does not require any equipment more specialized than a low-speed centrifuge, a microscope (with television camera, photographic camera, or camera lucidal, and a planimeter.

\section{References}

Allis, C.D., Y.S. Ziegler, M.A. Gorovsky, and J.B. Olmsted. 1982. A conserved histone variant enriched in nucleoli of mammalian cells. Cell 31: 131-136.

Allis, C.D., R. Richman, M.A. Gorovsky, Y.S. Ziegler, B. Touchstone, W.A. Bradley, and R.G. Cook. 1986. hvl is an evolutionarily conserved $\mathrm{H} 2 \mathrm{~A}$ variant that is preferentially associated with active genes. J. Biol. Chem. 261: 19411948.

Angerer, L.M. and R.C. Angerer. 1981. Detection of poly A+ RNA in sea urchin eggs and embryos by quantitative in situ hybridization. Nucleic Acids Res. 9: 2819-2840.

Bannon, G.A., F.J. Calzone, J.K. Bowen, C.D. Allis, and M.A. Gorovsky. 1983. Multiple, independently regulated, polyadenylated messages for histone $\mathrm{H} 3$ and $\mathrm{H} 4$ in Tetrahymena. Nucleic Acids Res. 11: 3903-3917.

Bannon, G.A., J.K. Bowen, M.-C. Yao, and M.A. Gorovsky. 1984. Tetrahymena H4 genes: Structure, evolution and organization in macro- and micronuclei. Nucleic Acids Res. 12: $1961-1975$.

Bhatnager, Y.M., M.K. McCullan, and R.B. Christopher. 1984. Immunocytochemical localization of a histone $\mathrm{H} 2 \mathrm{~A}$ variant in the mammalian nucleolar chromatin. Cell Biol. Intl, Rep. 8: 971-979.

Calzone, F.J., V.A. Stathopoulos, D. Grass, M.A. Gorovsky, and R.C. Angerer. 1983. Regulation of protein synthesis in Tetrahymena: RNA sequence sets of growing and starved cells. J. Biol. Chem. 258: 6905-6899.

Cameron, I.L. and D.M. Prescott. 1961. Relations between cell growth and cell division. V. Cell and macronuclear volumes of Tetrahymena pyriformis HSM during the cell life cycle. Exp. Cell Res. 23: 354-360.

Carmichael, G.G. and G.K. McMaster. 1980. The analysis of nucleic acids in gels using glyoxal and acridine orange. Methods Enzymol. 65: 380.

Childs, G., C. Nocente-McGrath, T. Lieber, C. Holt, and J.A. Knowles. Sea urchin (Lytechinus pictus) late-stage histone $\mathrm{H} 3$ and $\mathrm{H} 4$ genes: Characterization and mapping of a clustered but nontandemly linked multigene family. Cell 31: 383-393.

Cox, K.H., D.V. DeLeon, L.M. Angerer, and R.C. Angerer. 1984. Detection of mRNAs in sea urchins embryos by in situ hybridization using asymmetric RNA probes. Dev. Biol. 101: 485-502.

Doerder, F.P. 1979. Regulation of macronuclear DNA content in Tetrahymena thermophila. J. Protozool. 26: 28-35.

Donahue, P.R., D.K. Palmer, J.M. Condie, L.M. Sabatini, and M. Blumenfeld. 1986. Drosophila histone H2A.2 is associated with the interbands of polytene chromosomes. Proc. Natl. Acad. Sci. 83: 6878-6882.

Durkacz, B., A. Carr, and P. Nurse. 1986. Transcription of the cdc2 cell cycle control gene of the fission yeast Schizosaccharomyces pombe. EMBO I. 5: 369-373.

Gorovsky, M.A. 1973. Macro- and micronuclei of Tetrahymena pyriformis: A model system for studying the structure and function of eukaryotic nuclei. J. Protozool. 20: 19-25.

Gorovsky, M.A., M.-C. Yao, J.B. Keevert, and G. Lorick-Pleger. 1975. Isolation of micro- and macronuclei of Tetrahymena pyriformis. Methods Cell Biol. 9: 311-327.

Grunstein, M., M. Rykowski, D. Kolodrubetz, J. Choe, and J.
Wallis. 1984. A genetic analysis of histone protein subtypes in yeast. In Histone genes, pp. 35-63. Wiley, New York.

Hentschel, C.C. and M.L. Birnstiel. 1981. The organization and expression of histone gene families. Cell 25: 301-313.

Hill, R.J., T. Kroft, M. Zucker, and I.C.P. Smith. 1986. Largescale selection synchrony of Tetrahymena thermophila. I. Cell Sci. 84: 237-251.

Horowitz, S. and M.A. Gorovsky, 1985. An unusual genetic code in nuclear genes of Tetrahymena. Proc. Natl. Acad. Sci. 82: 2452-2455.

Horowitz, S., J.K. Bower, G. A. Bannon, and M.A. Gorovsky. 1986. Unusual features of transcribed and translated regions of the histone $\mathrm{H} 4$ gene family of Tetrahymena thermophila. Nucleic Acids Res. 15: 141-160.

Kaczmarek, L. 1986. Biology of disease. Protooncogene expression during the cell cycle. Lab. Invest. 54: 365-376.

McDonald, B.B. 1962. Synthesis of deoxyribonucleic acid by micro- and macronuclei of Tetrahymena pyriformis. I. Cell Biol. 13: 193-203.

Mitchison, J.M. 1971. The biology of the cell cycle. Cambridge University Press, London.

Nanney, D.L. 1980. Experimental ciliatology. Wiley, New York.

Prescott, D.M. 1960. Relation between cell growth and cell division. IV. The synthesis of DNA, RNA and protein from division to division in Tetrahymena. Exp. Cell Res. 19: $228-238$.

Prescott, D.M. and G.E. Stone. 1967. Replication and function of the protozoan nucleus. In Research in protozoology (ed. T.T. Chen), vol. 2, pp. 117-146. Pergamon Press, Oxford.

Schumperli, D. 1986. Cell-cycle regulation of histone gene expression. Cell 45: 471-472.

Singer, R.H., J.B. Lawrence, and C. Villnave. 1986. Optimization of in situ hybridization using isotopic and non-isotopic detection methods. BioTechniques 4: 230-250.

Thomas, P.S. 1983. Hybridization of denatured RNA transferred or dotted to nitrocellulose paper. Methods Enzymol. 100: $255-266$.

Woodard, J., E. Kaneshiro, and M.A. Gorovsky. 1972. Cytochemical studies on the problem of macronuclear subnuclei in Tetrahymena. Genetics 70: 251-260.

Wu, R.S., D. Nishioka, and W.M. Bonner. 1982. Differential conservation of histone $2 \mathrm{~A}$ variants between mammals and sea urchins. I. Cell Biol. 93: 426-431.

Wu, R.S., M.H.P. West, and N.M. Bonner. 1984. Patterns of histone gene expression in human and other mammalian cells. In Histone Genes pp. 457-483.

Yao, M.-C. and M.A. Gorovsky. 1974. Comparison of the sequences of macro- and micronuclear DNA of Tetrahymena pyriformis. Chromosoma 48: 1-18.

Yu, S.-M. and M.A. Gorovsky. 1986. In situ blots: Quantitation of mRNA in intact cells. Nucleic Acids Res. 14: 7597-7615. 


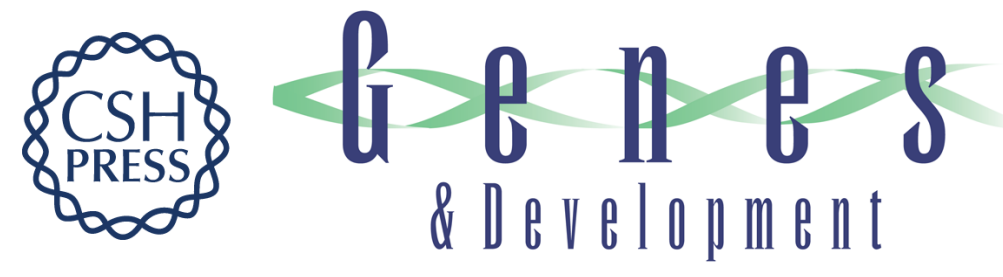

\section{A novel approach for studying gene expression in the cell cycle reveals coordinate and independent regulation of members of the $\mathrm{H} 4$ multigene family in cycling and in nongrowing Tetrahymena}

Genes Dev. 1987, 1:

Access the most recent version at doi:10.1101/gad.1.7.683

References

This article cites 29 articles, 7 of which can be accessed free at: http://genesdev.cshlp.org/content/1/7/683.full.html\#ref-list-1

License

Email Alerting Service

Receive free email alerts when new articles cite this article - sign up in the box at the top right corner of the article or click here.

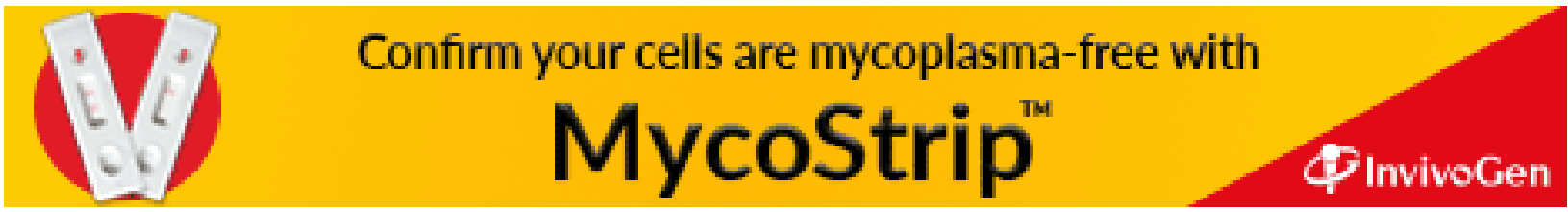

